\title{
I survive: COVID-19 patients' journey towards recovery
}

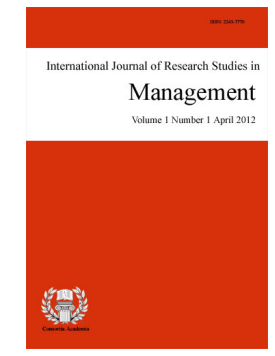

Balasta, Kathleen M.

Laguna College of Business and Arts, Philippines (kathleenbalasta@yahoo.com)

Accepted: 16 August 2021

ISSN: $2243-7770$

\section{Abstract}

This study investigated the lived experiences of twelve (12) COVID-19 survivors in the City of Sta. Rosa, Province of Laguna to explore their journey towards recovery. As an output of the study, a proposed detailed program was made to address the need of ensuring the psychological stability of the survivors. The research design used was qualitative with a phenomenology method as an approach. The researcher used the snowball sampling technique so that a particular participant can refer another participant with the same criteria as needed in the study. Using the interpretative phenomenological analysis, the study generated eight subordinate themes: unpleasant and fine experiences; significant and insignificant ones; various support; different ways of contriving; setting self-regulated activity; mixed emotions; psychological changes; prepared and aware; experiential advice. Under the first theme, it explored their experience while they were quarantined for fourteen days or more to recover from COVID-19. For the second theme, they were asked who were their support systems to help them overcome the illness and in what way. As for the third theme, the participants shared their reactions to dealing with the psychological effects of the disease caused by the pandemic. On the fourth theme, the participants were asked what alternative ways they have taken to overcome their condition. Under the fifth theme, they described their feeling when they were discharged from the quarantine facility or after their quarantine period. On the sixth theme, they were asked if their experience caused a change in their thoughts, emotions, and outlook on life as a COVID-19 survivor. For the seventh theme, they were asked if they are prepared now than before the pandemic. Lastly, they gave their advice to people who have experienced this type of illness. Awareness about Self-Introspection Mental Health of COVID-19 Survivors shall be strictly implemented and observed by the government agencies for better results.

Keywords: COVID-19 survivors, journey, recovery 


\section{I survive: COVID-19 patients' journey towards recovery}

\section{Introduction}

In the Philippines, more than 136,000 confirmed cases have been documented with 2200 deaths over a five-month period. Treatment approaches are evolving based on new evidence of the efficacy and safety of various drug and non-drug strategies. Containment measures in place since the middle of March 2020, including community quarantine and physical distancing, were aimed to slow down the spread of the infection (Tee et al., 2020). However, the needed shift in focus of mental health care has not been fully addressed due to the above restrictions. It is important to note that aside from the health aspect, the psychological state of every person during this time has a lot more to say.

On the interview of Elizabeth (a COVID19 survivor) conducted by Berg (2020), "I touched death and I'm very lucky to be alive. What I'm now looking forward to is appreciating nature. You realize material things don't matter. When I get outside I want to breathe the air, look at birds and enjoy the natural beauty of the world. I've been given a second chance". The narrated testimonies from Mercado (2020), Sahoo et al. (2020), Hohman (2020), Berg (2020), WHO (2020) and Metro Style (2020), gave an inspiring thought on recovering from COVID19. The journey wasn't easy but surviving makes them coming out stronger and ready to face life again. Prescott and Girard (2020), Mansoor et al. (2020) and Himss (2020) emphasize the importance of healthcare on the recovery of the COVID19 patients. Although situations will never be the same again on the condition of the latter, there is a need to have a positive perspective on the journey of COVID19 patients.

The COVID-19 pandemic has had a major effect on our lives. Many of us are facing challenges that can be stressful, overwhelming, and cause strong emotions on us. The University of Melbourne (2020), Health Wise Staff (2020), and Jesmi et al. (2021) stated that learning to cope with stress in a healthy way will make you, the people you care about, and those around you become more resilient thus, will help us recover from the aftermath of this disease. Above all, patients who recovered from COVID19 are lucky enough to face another chapter in their life. According to Olufadewa et al. (2020), Web Mb (2020) and Myupchar (2020), although the recovery time for the COVID19 patients is seemingly longer, there is a need for testing individuals for a more accurate information.

\section{Theoretical framework}

This study is anchored on the Self-determination theory and recovery-oriented practice by Ryan and Deci 2020. It suggests that human beings thrive and grow, achieve goals and feel greater well-being under conditions that support the fulfilment of basic human needs. A person's performance and well-being at work and at school, and their improvement and retention in treatment settings and in psychotherapy, have been shown to depend to a large degree on whether basic human needs are fulfilled. This study is also anchored on protection motivation theory R.W. Rogers in 1975 in order to better understand fear appeals and how people cope with them. It explained that people protect themselves based on four factors: the perceived severity of a threatening event, the perceived probability of the occurrence, or vulnerability, the efficacy of the recommended preventive behavior, and the perceived self-efficacy.

The recovery approach to life-changing conditions by Dr Eula Miller (2020) explains that recovery model of care views the individual holistically and focuses on maximizing their quality of life through social inclusion and community connectedness. The aim is to encourage skills development and promote independence and autonomy, serving to give patients hope for the future, promote successful community living and purposeful citizenship. This pragmatic approach is beneficial in sustaining wellbeing when engaging with patients who have chronic complex co-existing life-changing mental and physical health issues. 


\subsection{Research paradigm}

The journey towards recovery of COVID-19 survivor are identified through the two methods: the audio for the interviewers of the COVID-19 survivor which is recorded by the researcher and at the same time, field notes which are written and later on use on the verbatim transcription of the responses of the COVID-19 survivor in their journey towards recovery. Their statements are observed and evaluate to finally arrive on the idea about their experiences and how they cope on the situations they experience.



The study determined the experiences and journey towards recovery of the COVID-19 survivor. This lead into the development of proposed psychological program to raise awareness about introspection and mental health.

What is the essence of the lived experiences of the COVID-19 survivors?

\subsection{Corollary questions:}

$>\quad$ How do the participants describe their experience with regard to their experiences as COVID-19 positive and their journey towards recovery as survivor?

$>\quad$ What emerging themes arise from the study?

$>$ Based on the findings, what psychological program is recommended to raise awareness about self-introspection and mental health?

\subsection{Scope and delimitations}

The study looked into the experiences and journey towards recovery of COVID-19 survivor. The subject of the study was limited to twelve (12) COVID-19 survivors in City of Sta. Rosa, Province of Laguna. The line of questioning during the interview is limited to the purpose of extracting emerging themes that will arise from the study regarding the experiences and journey of COVID-19 survivor. It is relative to the experiences they have during the quarantine and explores the psychological state of the survivor. It will be conducted throughout the second semester of S.Y. 2020-2021.

\section{Review of related literature and studies}

The above collection of both foreign and local studies provides information as guide for the reference to present the emerging themes in the study. The materials will help the researcher in her discussion to clarify the problems investigated and the methods used in this study. The narrated testimonies from Mercado (2020), Sahoo et al. (2020), Hohman (2020), Berg (2020), WHO (2020) and Metro Style (2020), gave an inspiring thought on recovering from COVID19. The journey wasn't easy but surviving makes them coming out stronger and ready to face life again. Prescott and Girard (2020), Mansoor et al. (2020) and Himss (2020) emphasize the importance of healthcare on the recovery of the COVID19 patients. Although situations will never be the same again on the condition of the latter, there is a need to have a positive perspective on the journey of COVID19 patients.

The COVID-19 pandemic has had a major effect on our lives. Many of us are facing challenges that can be 
stressful, overwhelming, and cause strong emotions on us. The University of Melbourne (2020), Health Wise Staff (2020), and Jesmi et al. (2021) stated that learning to cope with stress in a healthy way will make you, the people you care about, and those around you become more resilient thus, will help us recover from the aftermath of this disease. Above all, patients who recovered from COVID19 are lucky enough to face another chapter in their life. According to Olufadewa et al. (2020), Web Mb (2020) and Myupchar (2020), although the recovery time for the COVID19 patients is seemingly longer, there is a need for testing individuals for a more accurate information.

\section{Methodology}

Research Design - The study utilized qualitative research with phenomenology as an approach. This strand of research is discovery-oriented, and the findings are not predetermined because variables were not manipulated; instead, it was emergent in design. Research questions at the onset, as well as data collection procedures or protocols may change along the way depending on what ongoing data collection and inductive data analysis reveal

Research instrumentation - In gathering pertinent information, the researcher used (8) guide questions as interview questions for COVID-19 survivor in City of Sta. Rosa, Province of Laguna. Thereafter, the researcher personally approached the co-researchers and explains the endeavor of her inquiry and the purpose of the interview. The interview started after the approval to conduct the interview. These are the questions,

(1) Ano ang iyong naging karanasan habang ikaw ay nakaquarantine sa hospital o bahay sa loob ng labing apat na araw o higit pa upang magpagaling dahil sa COVID-19? (What was your experience while you were quarantined for fourteen days or more to recover from COVID-19?)

(2) Sa panahon ng iyong pag-kakasakit ng COVID-19 sinu-sino ang mga naging kaagapay mo upang makatulong para malampasan mo ito? Sa paanong pamamaaan? (During your COVID-19 illness, who were your support system to help you overcome it? In what way?)

(3) Paano mo hinarap ang sikolohikal na mga epekto ng sakit na dulot ng pandemya? (How did you deal with the psychological effects of the disease caused by the pandemic?)

(4) Ano ang mga alternatibong paraan ang iyong ginawa upang malampasan ang iyong kondisyon? (What alternative ways have you taken to overcome your condition?)

(5) Paano mo maipapaliwanag ang iyong nararamdaman ng ikaw ay makalabas sa quarantine facility o matapos ang iyong quarantine period? (How do you describe your feeling when you discharged of the quarantine facility or after your quarantine period?)

(6) Ang iyong karanasan ba ay nagdulot ng pagbabago sa iyong kaisipan, emosyon, at pananaw sa buhay bilang COVID-19 survivor? Paano? At ano ang mga nabago nito sa iyong buhay pagkatapos mo ito malampasan? (Has your experience caused a change in your thoughts, emotions, and outlook on life as a COVID-19 survivor? How?) And what did it change in your life after you surpassed it?

(7) Base sa iyong karanasan, sa tingin mo ba naging preparado ka na ngayon kaysa dati? (Based on your experienced, do you think you are prepared now than before the pandemic?)

(8) Ano ang maipapayo na maibibigay mo sa mga tao na nakaranas ng ganitong uri ng sakit? (What advice can you give to people who have experienced this type of illness?)

Co-researchers of the Study - The researcher used snowball sampling method with twelve (12) selected COVID-19 survivors in the study.

Criteria in Selecting Participants - The first step in this process is to determine what common 
characteristics the participants should share. They should have been cleared already to be interviewed. Other related information about their status would be asked during the interview. The main criteria would include them having experienced of being a COVID-19 patient and have fully recovered.

Data Gathering Procedures - Proper coordination with COVID-19 patients to allow the researcher to proceed on the study, the researcher asked the latter to recommend some potential subject of the study. The researcher then discussed the reasons and goals of the study to the recognize participants upon giving endorsement as approval and sign for their confirmation as the subjects of the study. Thereafter, the interview sessions scheduled with the COVID-19 survivor who agreed to be the participants. In the arranged date, time and place a thorough interview conducted face-to-face which served as a data gathering instrument. The researcher then prepared recording gadgets, notes and pen and the guide questions before she facilitated the interview. After the interviews is the transcriptions, she proceeded with the encoding of the verbatim transcription that was based on the question answered by the participants, tabulation of data and qualitative data analysis to arrive at emerging themes. Health protocols would also have been considered during the data gathering procedure.

Treatment of Qualitative Data - After gathering all the data coming from the interviews to have been conducted, the researcher used Interpretative Phenomenological Analysis (IPA) as a method of analyzing the qualitative data. The researcher used the steps of IPA data analysis by Charlick et al. (2015) adapted from Smith et al., (2009). After transcribing the interview with the twelve (12) COVID-19 survivors, then, the researcher would start the data analysis by listening once more to the recording of the interview while reading the transcript. After reading and re-reading, the researcher would begin to note some initial ideas in a wide margin on the printed copy of the transcript. Afterwards, the emerging themes would be extracted. Then, certain themes would be naturally clustered together while others would be separated.

\section{Results and discussion}

In the course of the interview about their experiences towards their recovery, the researcher observed that the research participants 1 and 8 seemed so very emotional and sad with teary eyed during interview. This was supported in the article written by Palicte (2020), she mentioned the story of Dean Ortiz who test positive in COVID-19. Ortiz said that, "No facial expressions to draw emotions from, as if emotions had a place in the uncertainty I was faced with. The sound of my own heartbeat was very reassuring and I found myself saying a prayer."

When asked about their support system to helped them overcome their illness, the respondents have similar response. It was clearly observed that participants 2, 7 and 12 seemed to be happy from the support system they have received during their quarantine. It can be gleaned from the observation that despite of their experiences as COVID-19 survivors they were glad and contented. This conclusion and observation was braced by the news written by Mercado (2020) about Rogelio Bueno Jr. who had been infected by the dreaded disease and become COVID-19 patient number 358. He shared his story via Facebook post, he said that "I was already giving up and was preparing myself for the worse, my wife was crying but she kept saying, 'Laban, kaya mo yan!' She told me to pray together and just concentrate on getting better, telling me to repeat, 'Gagaling ako, may purpose pa ako." It can be concluded that throughout the journey of Bueno in COVID-19, his wife was totally in support to him.

When asked about on how the research participants deal with the psychological effects of COVID-19, from participant 1 , seems intense and emotional with teary eyed during the interview. On the other hand, participant 8 was emotional, teary eyed while remembering her struggle knowing that she's not with her children. While, participant 10 was very intense and emotional, teary eyed. It can be gleaned that participants have something in common in dealing with the psychological effects of COVID-19 which was emotional.

On the other hand, Participant 3 and 12 shared that their ways to overcome their condition was to exercise. Likewise, it can be gleaned that both participants were so proud and confident while stating their answers. 
Balasta, K. M.

Furthermore, Participant 3 and 12 shared that their ways to overcome their condition was to exercise. Likewise, it can be gleaned that both participants were so proud and confident while stating their answers.

Based from the responses of the research participants 1 and 3 on the experiences caused changes in their thoughts, emotions, and outlook in their life as COVID-19 survivors, participants responded that, "Hindi mo talaga masasabi kung hanggang kailan ka lang kaya andun ako sa part na, na...sabi ko kailangan ienyoy mo ang buhay.." said Participant 1, while participant 3 said that, "Minsan lang naman iyon parang nagtatanong ako sa sarili ko na para bang bakit walang support..". It can be seen and observed from both participants that they were serious when they shared their experiences.

When asked about the research participants if they are prepared now than before the pandemic, participants happily answered that, participant 5 answered that "Sa ngayon preparado na kami dahil nga sa dami na rin ng aming nakaharap namin naging karanasan naming kailangan handa kami katulad nga nung unang vaccine na binigay sa amin.." On the other hand, participant 9 mentioned the do's and don't such as observance of social distancing and eating healthy fruits and vegetables.

When asked about the research participants of what advice they can give to the people who have experienced that kind of illness, Participant 3 advised that, have strong faith with God because in Him everything is possible, be careful, and wear protective devices such as face shield and face mask. While participant 5 , advised not to be negative in time of distress.

For the corollary question number 2, the emerging themes from the testimonies of the COVID-19 survivors.

The chart that follows provide the themes that emerged from the different responses of the COVID-19 survivors and their journey towards recovery.

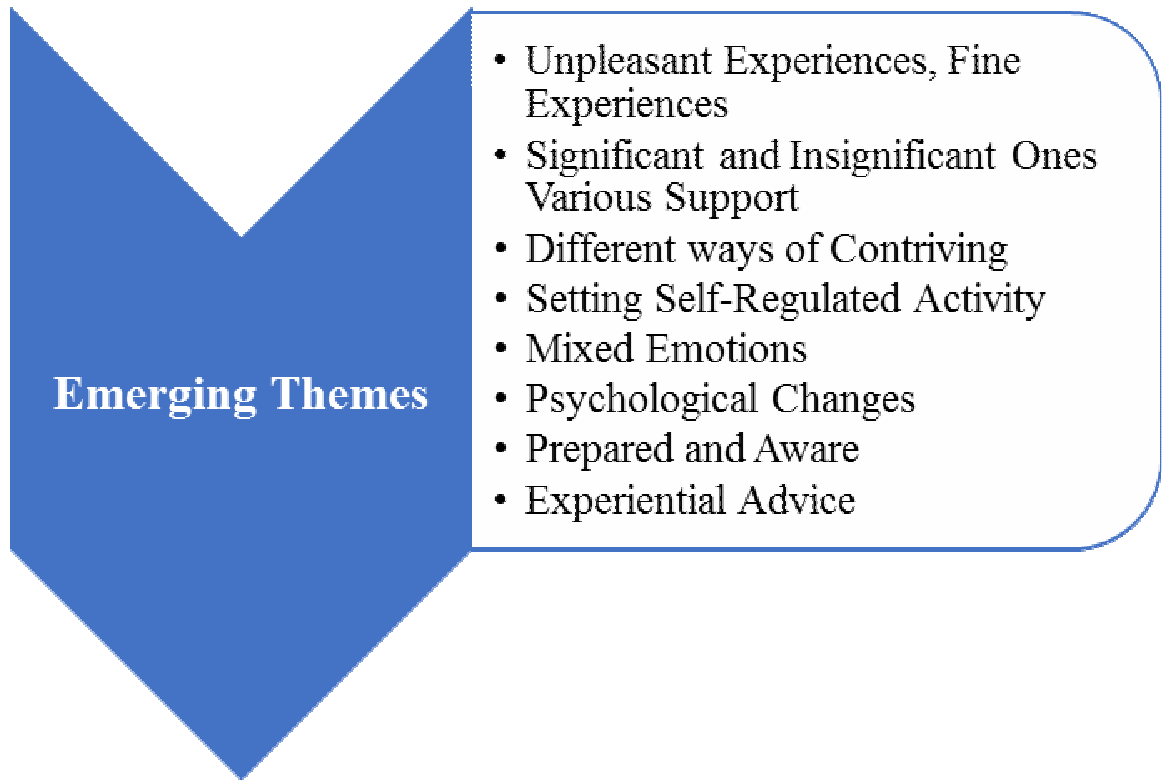

\section{Conclusions}

The following are the consolidated findings based on the interviews with the research participants and emerging themes that arise from the phenomenological inquiry on the testimonies of the COVID-19 survivors and their journey towards recovery. COVID-19 survivors shared almost the same stories about their experiences and their journey towards recovery. There were eight (8) emerging themes developed based from the responses of the participants. Below are the emerged themes:

66 Consortia Academia Publishing (A Partner of Tourism Educators and Movers of the Philippines) 
Unpleasant Experiences, during the fourteen-day quarantine of the participants in the center or facility, they were unprepared on the situation, felt miserable and distress, and felt bored. These unpleasant experiences were very much evident and observed by the researcher during the interview. Second, some participants were fine as they shared their experiences.

Significant and Insignificant Ones Various Support were the support system received and acknowledge among the participants. It was their family, friends, Midwife, and Brgy Captain who provided different supports through communication, relief goods, and moral.

Participants dealt with the psychological effects brought by the disease caused by pandemic through different ways of contriving. This was divided into three (3) subordinate themes such as acceptance and positivity, finding strength on others, and stress management.

In order for the participants to overcome the situation, setting self-regulated activities was emerged to the theme. And this was divided into two (2) subordinate themes, physical exercises and entertainment, and positive thinking. Furthermore, participants described their experiences and feelings when they get to discharge from the quarantine facility to three (3) subordinate themes, (1) happy, (2) cautious, and (3) mixed feelings.

Psychological changes have been emerged as caused by their experiences which led change in their thought, emotion, and outlook in life. Likewise, subordinate themes have been emerged as self-awareness, and positive thinking. Based on their experiences, participants are more now prepared than before pandemic. Aside from experiences, available vaccines were the consideration on the increase of their preparedness. On the note, research participants gave experiential advice to people who have experienced this type of illness. They also added to hold on their faith, pray to God, proper disinfection, and be obedient at all times. The researcher has come up with the following reflections based on the findings of the study about the essence of the lived experience of COVID-19 survivors and their journey towards recovery. COVID-19 illness may bring unpleasant experiences but family, friends, and local government officials will serve as support not only financially, mentally, but psychologically. In addition, when hit by COVID-19, find strength with one another, with your family and friends. Try to find positive thoughts in everyday living.

\section{References}

Amsalem, D., Dixon, L. B., \& Neria, Y. (2020). The Coronavirus Disease 2019 (COVID-19) outbreak and mental health. JAMA Psychiatry. https://doi.org/10.1001/jamapsychiatry.2020.1730

Berg, R. (2020). A coronavirus survivor's story: I touched death. https://www.bbc.com/news/uk-52353275

Caliwan, C. L. (2020). COVID-19 survivors' tales: Isolated but not neglected. Philippine News Agency. https://www.pna.gov.ph/articles/1118735

Cervantes, F. (2021). Over 1.3 M Filipinos vaccinated against COVID-19. Philippine News Agency. https://www.pna.gov.ph/articles/1137535

Chadambaram, P. (2020). The implications of COVID-19 for mental health and substance use. https://www.kff.org/coronavirus-COVID-19/issue-brief/the-implications-of-COVID-19-for-mental-heal th-and-substance-use/

Coronavirus Disease 2019. (COVID-19). (2020). Centers for disease control and prevention. https://www.cdc.gov/coronavirus/2019-ncov/daily-life-coping/managing-stress-anxiety.html

Coronavirus Recovery. https://www.webmd.com/lung/COVID-recovery-overview\#2

Coronavirus. (COVID-19): Managing stress and anxiety. The University of Melbourne.

Corp., A. (n.d.). Exclusive! Iza Calzado: I was COVID-19 patient 878, and here's my story of survival. Metro.Style. https://metro.style/people/digital-covers/iza-calzado-COVID-19-recovery-cover-story/24542

Creswell, J. W. (2013). Qualitative inquiry \& research design: Choosing among the five approaches. Thousand Oaks, CA: SAGE.

Fegert, J. M., Vitiello, B, Plener, P. L., \& Celemns, V., (2020). Challenges and burden of the Coronavirus 2019 
(COVID-19) pandemic for child and adolescent mental health: A narrative review to highlight clinical and research needs in the acute phase and the long return to normality. https://doi.og/10.1186/s13034-020-00329-3N

Headquarters, W. (2020). Critical preparedness, readiness and response actions for COVID-19. WHO. https://www.who.int/publications/i/item/critical-preparedness-readiness-and-response-actions-for-COVI D-19

Health Wise Staff. (2020). Give yourself a break: practicing self-compassion. https://www.uofmhealth.org/health-library/acl3306

Importance of physical activity and exercise during the COVID-19. (2020). Psychiatry. https://medicine.umich.edu/dept/psychiatry/michigan-psychiatry-resources-COVID-19/your-lifestyle/im portance-physical-activity-exercise-during-COVID-19-pandem

Janiri, D., Kotzalidis, G., Giuseppin, G., Molinaro, M., Modica, M., Montanari, S., Terenzi, B., Carfì, A., Landi, F., \& Sani, G. (2020). Psychological distress after COVID-19 recovery: Reciprocal effects with temperament and emotional dysregulation. An exploratory study of patients over 60 years of age assessed in a post-acute care service. https://doi.org/10.3389/fpsyt.2020.590135

Jesmi, A. A., Mohammadzade-Tabrizi, Z., Rad, M., Hosseinzadeh-Younesi, E., \& Pourhabib, A. (2021). Lived experiences of patients with COVID-19 infection: A phenomenology study. Medicinski Glasnik, 18(1). https://doi.org/10.17392/1247-21

Mansoor, T., Mansoor, S., \& Zubair, B. (2020). Surviving COVID-19': Illness narratives of patients and family members in Pakistan. Annals of King Edward Medical University, 26(Special Issue), 157-164.

Mercado, N. A. (2020). Another COVID-19 patient tells story of survival. https://newsinfo.inquirer.net/1250860/another-COVID-19-patient-tells-story-of-survival

Mesias, S. (2021). Taal survivor shares how they survived 2020. World Vision Philippines. https://www.worldvision.org.ph/stories/midona-story/

Miller, E. (2020). Clinical: The recovery approach to life-changing conditions. https://www.nursinginpractice.com/latest-news/clinical-the-recovery-approach-to-life-changing-conditi ons/

Myupchar (2020). Life after COVID-19: What the road to recovery from the coronavirus looks like. https://www.firstpost.com/health/life-after-COVID-19-what-the-road-to-recovery-from-the-coronavirus -looks-like-8398841.html

Olufadewa, I., Adesina, M., Oladokun, B., Baru, A., Oladele, R., Iyanda, T., Ajibade, O., \& Abudu, F. (2020). I was scared I might die alone: A qualitative study on the physiological and psychological experience of COVID-19 survivors and the quality of care received at health facilities. International Journal of Travel Medicine and Global Health, 8(2), 51-57. https://doi.org/10.34172/ijtmgh.2020.0

Palicte, C. (2020). Renewed faith: Tale of a COVID-19 survivor. Philippine News Agency. https://www.pna.gov.ph/articles/1121158

Prescott, H., \& Girard, T. (2020). Recovery from severe COVID-19 leveraging the lessons of survival from sepsis. https://jamanetwork.com/journals/jama/fullarticle/2769290

Protection Motivation Theory. https://en.wikipedia.org/wiki/Protection_motivation_theory

Reyes, C. (2020). Coping with the new normal how to adapt to change and prioritize the things that truly matter. https://www.fwd.com.ph/en/live/all_topics/all_articles/coping-with-the-new-normal/

Ryan, R. M., \& Deci, E. L. (2000). Self-determination theory and the facilitation of intrinsic motivation, social development, and well-being. American Psychologist. https://selfdeterminationtheory.org/SDT/documents/2000_RyanDeci_SDT.pdf

Sahoo, S., Mehra, A., Suri, V., Malhotra, P., Yaddanapudi, L. N., Dutt Puri, G., \& Grover, S. (2020). Lived experiences of the corona survivors (Patients admitted in COVID wards): A narrative real-life documented summaries of internalized guilt, shame, stigma, anger. Asian Journal of Psychiatry, 53. https://doi.org/10.1016/j.ajp.2020.102187

Sahoo, S., Mehra, A., Suri, V., Malhotra, P., Yaddanapudi, L. N., Puri, G., \& Grover, S. (2020). Lived experiences of COVID-19 intensive care unit survivors. Indian Journal of Psychological Medicine, 42(4), 
387-390. https://doi.org/10.1177/0253717620933414

Siddaway, A. P. (2020). Multidisciplinary research priorities for the COVID-19 pandemic: A call for action for mental health science. Lancet Psychiatry, 7(7). https://doi.org/10.1016/S2215-0366(20)30220-0

Tanoue, Y., Nomura, S., Yoneoka, D., Kawashima, T., Eguchi, A., Shi, S., Harada, N., \& Miyata, H. (2020). Mental health of family, friends, and co-workers of COVID-19 patients in Japan. Psychiatry Research, 291, 113067. https://doi.org/10.1016/j.psychres.2020.113067

Tantuco, V. (2020). 7 lessons on self-isolation from COVID-19 survivors. Rappler. https://www.rappler.com/newsbreak/iq/lessons-self-isolation-COVID-19-survivors

Tee, C. A., Salido, E. O., Reyes, P. W. C., Ho, R. C., \& Tee, M. L. (2020). Psychological state and associated factors during the 2019 Coronavirus Disease (COVID-19) Pandemic among Filipinos with rheumatoid arthritis or systemic lupus erythematosus.

https://www.dovepress.com/psychological-state-and-associated-factors-during-the-2019-coronavirus-pe er-reviewed-fulltext-article-OARRR

The effect of COVID-19 on mental health and wellbeing in a representative sample of Australian adults. (2020). Frontiers. https://doi.org/10.3389/fpsyt.2020.579985

The implications of COVID-19 for mental health and substance use. (2020).

$K F F$. https://www.kff.org/coronavirus-COVID-19/issue-brief/the-implications-of-COVID-19-for-menta 1-health-and-substance-use

UNICEF Serbia. Retrieved June 7, 2021, from https://www.unicef.org/serbia/en/how-cope-new-situation-during-COVID-19-epidemic

University of Melbourne. (2020). Coronavirus (COVID-19): Managing stress and anxiety. https://services.unimelb.edu.au/counsel/resources/wellbeing/coronavirus-COVID-19-managing-stress-a nd-anxiety

WHO survey. (2020). COVID-19 disrupting mental health services in most countries. World Health Organization. https://www.who.int/news/item/05-10-2020-COVID-19-disrupting-mental-health-service s-in-most-countries-who-survey

WHO. (2020). COVID-19 in the Philippines situation report 65.

https://www.who.int/philippines/internal-publications-detail/COVID-19-in-the-philippines-situation-rep ort-65

WHO. (2020). It didn't kill me, but i came out stronger. https://www.who.int/news-room/feature-stories/detail/it-didn-t-kill-me-but-i-came-out-stronger

Wikipedia. (2020). COVID-19 Pandemic in the Philippines. https://en.wikipedia.org/wiki/COVID-19_pandemic_in_the_Philippines

Wolman, R. (2020), Blog: The role of exercise in COVID-19 https://www.wlv.ac.uk/news-and-events/latest-news/2020/august-2020/blog-the-role-of-exercise-in-CO VID-19.php 
Balasta, K. M.

70 Consortia Academia Publishing (A Partner of Tourism Educators and Movers of the Philippines) 